\title{
O que a ginástica artística tem de artística? Considerações a partir de uma análise estética
}

CDD. 20.ed. 796.41

\section{Resumo}

A terminologia, Ginástica Artística, sugere um grande papel estético para a modalidade e aponta um cruzamento entre o fenômeno esportivo e a arte. 0 presente artigo busca discutir as premissas desse cruzamento e coloca em pauta conceitos do campo da estética e constatações observadas no contexto atual desse esporte. Nota-se que uma das grandes riquezas da modalidade reside justamente na união desses dois fenômenos, mas que na realidade prática o conteúdo artístico tem sido negligenciado, pouco valorizado ou subaproveitado. 0 Brasil pode deixar a sua marca no cenário mundial da Ginástica Artística através da combinação, do hibridismo e da inventividade que são características da estética brasileira e que podem influenciar o conteúdo expressivo e artístico deste esporte.

Palavras-chave: Estética; Ginástica artística; Arte; Código de pontuação.

\section{Introdução}

Apesar do processo de mudanças pelo qual passou no decorrer dos anos, a Ginástica Artística (GA) continua vividamente expressiva e criativa e revela sua aproximação com a arte ${ }^{1}$. De acordo com ARKAEV E SuCHLIN" a GA está conectada com a "arte do movimento".

PALMER $^{2}$ reflete que a atual nomenclatura instiga algumas das questões problemáticas sobre como este esporte poderia ser compreendido como sendo artístico. E, como o produto artístico de uma performance poderia ser sensivelmente avaliada.

Podemos supor, portanto, que essa manifestação de ginástica, ainda que atenda aos preceitos de um esporte, mantenha de algum modo uma relação com a arte. Mas, quais seriam essas relações? A denominação é lícita ou se trata apenas de uma aproximação falaciosa entre fenômenos distintos? De fato, uma vez que as questôes artísticas da ginástica raramente são objeto de pesquisa, de certa forma, sentimo-nos incomodados e duvidosos sobre a pertinência desse termo.

Conforme BorTOLETO ${ }^{3}$, a GA possui uma característica estética inerente e significativa que lhe garantiu, em grande medida, o sucesso adquirido ao longo dos tempos. Essa questão estética da GA advém dos primórdios da modalidade. Powell citado por Palmer e Sellers ${ }^{4}$ cita que Aristóteles já relacionava a ginástica, compreendida como a prática de atividade física, com a arte o que nos permite inferir que desde o período clássico há uma reflexão sobre o componente artístico da GA na sua essência. Corroboramos Palmer e Sellers ${ }^{4}$ que esse aspecto, talvez, não seja suficiente para reivindicar o componente artístico da modalidade, mas indica que havia características apreciáveis de caráter estético na atividade gímnica daquele período que, no decorrer de muitos séculos, passou por mudanças significativas advindas de profundas transformaçōes socioculturais e políticas, que influenciaram a constituição da GA no momento atual'.

O rigor técnico e a evolução esportiva da GA apontam para horizontes menos artísticos, mais funcionalistas ou produtivos com vista ao alto rendimento. Talvez a arte, com sua costumeira abstração, não tenha espaço no pragmatismo do treinamento dessa modalidade esportiva que, a cada dia, eleva os seus critérios de avaliação técnica, conforme podemos observar em Oliveira e BORTOLETO ${ }^{6}$ e na própria concepção do Código de Pontuação atual. É possível inferirmos que
*Faculdade de Educação Física, Universidade Estadual de Campinas.

**Instituto de Artes Universidade Estadual de Campinas.

***Escola de Educação

Física e Esporte de Ribeirão Preto, Universidade de São Paulo. 
esse incremento nos critérios de avaliação intencione estabelecer parâmetros diferenciadores, pois a nota máxima 10, que deixou de existir com o Código de Pontuação aberto, parecia não atender mais a este propósito como fora outrora. Por outro lado, a falta de uma nota máxima, limite atingível, fez com que técnicos e atletas buscassem estratégias para elevar o grau de dificuldade de suas séries e cometer o mínimo de erros na execução. E, uma dessas táticas, foi acrescentar elementos acrobáticos complexos e suas ligaçōes. Desta forma, talvez a arte, a coreografia, a dança, a criação, tiveram que ceder espaço para os elementos que aumentariam o potencial da nota de dificuldade dos ginastas. Na opinião de Oliveira e BORTOLETO $^{6}$, estes aspectos foram marginalizados no processo de avaliação o que influenciou a conduta de técnicos e atletas na GA atual.

Podemos perceber que talvez a faceta atlética da GA tenha se desenvolvido mais em sua evolução esportiva, contudo, ainda há elementos que demarcam a presença da arte nessa manifestação.

Essa presença da arte nas performances gímnicas está relacionada aos aspectos estéticos da graça, beleza, plasticidade, elegância, postura, leveza, ritmo, harmonia e controle. Essas características estão diretamente ligadas ao virtuosismo que, segundo a FEDERAÇÃo InTERNACIONAL DE GinÁSTICA ${ }^{7}$, manifestam-se quando o ginasta demonstra elegância particular na execução, leveza no desenvolvimento dos movimentos e maestria na dificuldade e no risco. E, também, referem-se à originalidade que consiste em novas formas de movimento, de partes ou ligaçóes de exercícios que, como tais, são novas e se destacam nos quadros do que é conhecido, tradicional ou clássico nas séries ${ }^{8}$. Na concepção de Oliveira e BORTOLETO ${ }^{6}$, esses dois fatores, por não serem valorizados na nota de dificuldade, permanecem às margens do Código de Pontuação. Talvez, por isso, os códigos vigentes ${ }^{9-10}$ não definam esses fatores que, no período atual, não recebem bonificaçōes específicas como no passado. Atualmente, na GA feminina, as ginastas podem ser penalizadas na apresentação artística das séries, porém não recebem acréscimos na nota por transformarem seus movimentos em arte, poesia e beleza.

Nesse sentido, torna-se importante e urgente não somente resgatar a compreensão desses temas em torno do conceito de GA, mas também propor novas reflexões que nos levem a compensar o desenvolvimento desequilibrado da modalidade, quiçá agora vislumbrar maior atenção aos valores estéticos.

Surpreendentemente, apesar do pouco valor atribuído ao componente artístico na composição da série no momento da preparação de ginastas, particularmente no setor masculino, este é um critério julgado e pontuado pelos árbitros, pois a criatividade, o virtuosismo e a harmonia das séries influenciam no momento de avaliação ${ }^{2}$. Ainda mais curioso é que muitos árbitros não recebem orientação para julgar este componente ${ }^{11}$, o que torna o processo avaliativo também subjetivo e equivocado.

A posição assumida nesse texto não é a da defesa apaixonada da GA, sintoma comumente presente nas discussōes sobre o tema, pois o esporte, mais do que um objeto de estudo é, também, um catalisador de paixões. Por outro lado, não se trata de uma dissecação sistemática com o fim último de desmerecer uma prática consolidada por meio da mera análise de sua denominação. Acreditamos ser mais produtiva uma compreensão que situe a reflexão na própria prática do fenômeno e que, com isso, busque não apenas o que está expresso, mas, também, o que se oculta. Por isso, elegemos a Estética como forma de abordagem e interpretação.

A Estética é um dos ramos da Filosofia e seus objetos de estudo são a beleza, a sensibilidade e as formas de produção do sensível. O que a torna peculiarmente interessante para reflexões como a que este texto propõe é o fato de que o seu olhar não se restringe à produção estritamente artística, ou seja, a beleza presente em qualquer fenômeno natural ou social é de interesse sistemático da Estética. Soma-se a essa vantagem o dado que a Estética, em seu discurso sobre a beleza, produz uma reflexão de interesse filosóficocientífico. Por vezes, discursos sobre a beleza, sobretudo, aquela presente no cotidiano, correm o risco de serem cooptados pelo relativismo do "gosto", ou seja, por um tipo de discurso que submete o objeto de estudo a um subjetivismo extremo do qual pouco se pode extrair em termos filosóficos e científicos. PIRES ${ }^{11}$ parece identificar que é exatamente o que ocorre na avaliação do componente artístico na GA. Este fica subordinado ao que atrai ou coincide com o gosto do árbitro, pois as entrevistas desse estudo confirmaram que eles não têm critérios para diferenciar tal componente. E, tampouco, foram instruídos para este fim.

A reflexão Estética exige compreensibilidade e, justamente por isso, é um suporte eficaz em um estudo sistemático sobre a beleza contida em determinado fenômeno. Como aponta SUASSUNA ${ }^{12}$, "a Estética é uma espécie de reformulação da Filosofia inteira em relação à beleza e à arte" (p.23).

Passemos então a submeter as características da GA a uma análise Estética para, com isso, realizarmos uma discussão sobre a relação entre o artístico e a GA. 


\section{Que beleza produz a ginástica artística?}

Uma vez que a Estética coloca toda a reflexão filosófica a serviço de sua análise é preciso, também, que se eleja certo recorte filosófico para tal. Pensadores diversos elegeram teorias e métodos sobre Estética, muitos deles, inclusive, divergentes. Como não se trata aqui de esmiuçar essas vertentes, partiremos de conceitos mais ou menos gerais no campo da Estética que, de um modo ou de outro, são passagens elementares na constituição desse ramo de estudo e que, para uma abordagem introdutória, serão certamente suficientes. Assim, nossa pergunta inicial deve situar-se no conceito de belo/beleza. Tal conceito carrega em si a noção de agradável aos sentidos ou de perfeição expressiva ${ }^{13-17}$.

A GA oferece, comumente, certo deleite expressivo? Pelos indícios empíricos que envolvem a modalidade podemos afirmar que sim. As vinhetas televisivas, por exemplo, entre outros recursos de "marketing" sobre competições esportivas como as Olimpíadas costumam ser entremeadas de imagens de acrobacias da GA. Ainda que o grande público não compreenda em detalhes as regras que guiam a competição, parece que há certo prazer em se contemplar os movimentos oriundos das séries. Ora, nesse sentido, encontramos um primeiro elemento que nos ajuda a trilhar o caminho da reflexão estética sobre essa modalidade: o caráter desinteressado. Embora, em uma primeira análise, pareça muito mais conveniente para os profissionais que atuam na GA que o público em geral compreenda, à medida do possível, as regras da competição ${ }^{18-20}$, a simples contemplação desinteressada é um atributo que, do ponto de vista estético, valoriza a GA como fenômeno.

Vários esportes seriam demasiado entediantes se não soubéssemos os objetivos de suas regras, mas, com a GA, justamente pelo seu critério intrínseco de beleza e espetáculo (as acrobacias expressam coragem, risco, o que poderia ser associado a um espetáculo de circo, por exemplo), pode até ocorrer o contrário. Talvez, por isso, um esforço também necessário seja o desenvolvimento da atenção constante para que as regras sempre revistas dos Códigos de Pontuação, que guiam as competições, não empalideçam o tom de espetacularidade da modalidade.

É comum, por exemplo, que na composição de uma série, opte-se por uma justaposição de elementos de dificuldade técnica mais valorizada sem, contudo, considerar a harmonia geral da série, o que pode gerar um resultado no qual a apresentação mais "bela" não seja, necessariamente, a mais valorizada. É importante fazer uma ressalva sobre o equilíbrio, que na opinião de Oliveira e BorTOLETO ${ }^{6}$, consiste no maior desafio que a Federação Internacional de Ginástica (FIG) enfrenta na atualização dos Códigos de Pontuação, pois, manter essa relação entre esporte e arte é uma tarefa difícil.

Não estamos defendendo os preceitos estéticos em detrimento dos valores técnicos, mas, argumentando que se já na pergunta mais geral a que nos remete uma análise estética encontramos explícitos os elementos aparentes da GA, há de se proceder conscientemente para que tais elementos sigam em paridade com o desenvolvimento técnico da modalidade, a fim de preservar esse importante diferencial que caracteriza a GA.

Em suma, pensamos tratar-se de conciliar dificuldade técnica e beleza, exigência esportiva e deleite estético e, se possível, chegar ao pódio. Ainda com base nas entrevistas aplicadas aos técnicos de GA por PIRES ${ }^{11}$, podemos notar que eles atribuem valor estético aos elementos tecnicamente perfeitos e, não necessariamente, aos componentes como harmonia, equilíbrio e expressividade. Estes aspectos, embora sejam regulamentados pelo Código de Pontuação, são pouco valorizados e tampouco são destacados nos cursos preparatórios de árbitros da modalidade.

Ao avançar um pouco mais na reflexão, ou radicalizá-la, no sentido de se buscar a raiz da questão, uma abordagem estética que nos parece especialmente adequada para entender o equilíbrio enunciado anteriormente, após a pergunta inicial, e também os desdobramentos argumentativos posteriores é a teoria nietzschiana sobre a arte. Ao analisar, especificamente, o nascimento da tragédia na cultura grega, Nietzsche oferece-nos um modelo de compreensão estética aplicável a muitos outros fenômenos, em especial, àqueles que se encontram divididos por forças opostas, porém complementares. No âmbito da sociedade grega, Nietzsche encontrou essas forças no deus Apolo de um lado e em Dionísio de outro ${ }^{21}$. As forças apolíneas são aquelas que valorizam a forma, a harmonia e a retidão, já o dionisíaco exalta a força, o êxtase e a energia. $\mathrm{O}$ racionalismo pós-socrático e o moralismo cristão fizeram com que o apolíneo se sobrepusesse ao dionisíaco nas culturas ocidentais, enaltecendo sempre mais os valores da forma do que os do entusiasmo.

$\mathrm{E}$, não é exatamente esse o caso do equilíbrio estético na GA? O século XIX, o mesmo de Nietzsche, foi especialmente capaz de produzir nos corpos, por meio da ginástica, uma retidão e um equilíbrio apolíneo altamente estruturado e duradouro. Nesse 
âmbito, os estudos de SOARES ${ }^{22-23}$ são profícuos em discutir as características das ginásticas do Século XIX que influenciaram a constituição da GA e que deixaram marcas que estão encarnadas até o momento atual e, assim, percebermos como o fator apolíneo tende à predominância na modalidade.

Uma vez que argumentamos em torno de uma visão estética na GA, cuja análise se pretende em algum grau propositiva, temos que pensar no equilíbrio entre tais forças. Caso tenha havido, historicamente, uma supervalorização do apolíneo, temos que considerar como provavelmente necessária uma prática mais dionisíaca. Entretanto, para os limites desta seção, basta percebermos que essa divisão estética (apolíneo-dionisíaca) é bastante clara na GA, o que já nos revela, de partida, como são possíveis e pertinentes reflexões estéticas sobre essa modalidade. A GA produz, de fato, beleza. Analisar essa beleza e propor formas de incrementá-la é um desafio estético que não cabe a outros senão àqueles diretamente envolvidos em sua teoria e prática.

Ao olhar do avaliador, como foi apontado, parece que ele valorizará aquilo que lhe impressiona, que prende a atenção de alguma forma. Esta "dualidade" apolíneo-dionisíaca pode ser explorada pelos ginastas de modo que seja interpretada pelos avaliadores como capacidade de expressão artística que ultrapassa o convencional.

\section{Endurecimento, pressa e a arte da mesmice}

Então, como uma modalidade que é intrinsecamente ligada à beleza poderia produzir um resultado estético que não corresponda a essa associação? Em parte, pela própria distorção que o caráter competitivo e, por extensão, a ansiedade em satisfazê-lo, podem trazer ao cenário da GA.

A competição, por si só, não pode ser responsabilizada por essa falta, mas a forma como lidamos com ela, ou, mais especificamente, o modo como relacionamos esporte, competição e estética é que revela as linhas desviantes desse encontro.

Um trabalho artístico, assim como o esportivo, deve ser construído sem a pressa de quem quer cumprir uma tarefa imediata, desconectada do todo. É preciso instituir-se uma visão de conjunto que, se no caso da arte é o próprio objeto de arte, no esporte competitivo é a competição ou evento esportivo para o qual o atleta está se preparando. $\mathrm{O}$ problema, a partir dessa afirmação, é que a GA, por ser um cruzamento desses dois fenômenos, exige um cuidado ainda maior na sua composição harmônica.

Um modelo razoavelmente disseminado de treinamento em GA e Ginástica Rítmica é a divisão das sessões de treino entre exercícios de incremento de força e flexibilidade, conteúdo técnico específico e preparação artística. Detenhamo-nos nesse modelo buscando, como proposto, realizar uma leitura fundamentada na Estética.

A preparação física é um pilar fundamental na prática da GA competitiva, como é evidenciado por NunOmURA et al. ${ }^{24}$. Este estudo revelou que os técnicos não dispensam tempo satisfatório para a preparação artística que inclui aulas de balé, dança, teatro, contemplação de arte, etc. A justificativa é a falta de tempo ou detrimento de um componente (preparação artística) em favor de outro (preparação técnica, física, psicológica) que se julga mais importante.

Devemos ressaltar que uma maior preocupação com os aspectos estéticos presente no treinamento em GA, não deve supor a eliminação desse tipo de intervenção voltada para os aspectos técnicos, físicos e psicológicos, mas, repensar o modelo que se oferece. As sessōes de treinamento assumem posturas "endurecidas", e elegem a mecanização de movimentos por meio de um treino longo e exaustivo no qual os sacrifícios são considerados necessários para a obtenção de resultados. Mais uma vez, ressaltamos que não é intuito desse texto colocar em questão esses modelos, pois nos exigiria um deslocamento de referência e a busca de comprovações empíricas sobre a eficiência de um ou outro protocolo de treinamento. Entretanto, ao aplicar nossa metodologia de análise, entendemos que esse modelo "endurecido" de treinamento também tem seu viés estético e é ele que nos interessa para a argumentação em curso.

Diferentemente de outras expressões esportivas, nas quais os movimentos são realizados mediante explícito esforço, uma das características da GA é a de lidar com movimentos de alto grau de dificuldade com uma qualidade de execução que, grosso modo, nos faz parecer que não houve esforço envolvido. Lembremo-nos que a GA conta com a presença de árbitros que avaliam as séries e que terão como parâmetro, entre outros fatores, o domínio total do movimento. Assim, essa "facilidade" aparente na 
execução da série seria um reflexo do domínio associado ao bom preparo técnico e físico. A "segurança" do ginasta na execução da série, também, é requisito essencial e associado a esse domínio do movimento. Um movimento em que o/a ginasta não demonstra domínio e não esteja preparado/a para executá-lo, potencialmente, poderá colocá-lo/a em risco. E, nenhum movimento que ofereça risco deverá ser objeto de apresentação em competição. O próprio Código de Pontuação foi elaborado com base nessa lógica.

Nessa "segurança" está explícita a aparência do gesto, ou seja, todo o conjunto de fatores estéticos que ajudam a compor o movimento final. Assim, uma sessão de treino "endurecida" é um dos pontos de partida para a composição de gestos "embrutecidos", não característicos do que se espera de uma série de GA bem executada e harmônica.

Infelizmente, este embrutecimento da GA está cada vez mais prevalente e parece sinalizar uma tendência atual dessa modalidade. Uma causa provável pode ser o nível de competitividade em ascensão.

Pensamos que, desde a preparação inicial até o treinamento pré-competitivo, os fatores estéticos podem e devem ser considerados no processo de preparação de ginastas, propondo-se sessōes de treino que sejam permeadas pelos aspectos estéticos que o produto final da GA requer, ou seja, movimentos harmoniosos, seguros e bem executados. Acreditamos que não devam existir contrassensos entre os diferentes componentes do treinamento. Podemos citar, como exemplo, a preparação física que não deve estar apartada dos aspectos estéticos da modalidade. O ginasta deve realizar os exercícios físicos com boa técnica e execução com vista ao estabelecimento futuro da maestria dos movimentos específicos nos aparelhos.

Por essa mesma via de reflexão, podemos analisar, também, as aulas complementares de balé que, no caso da GA feminina, recebe significativa atenção na preparação coreográfica ${ }^{1}$. Segundo a $\mathrm{FIG}^{25}$, a capacidade do ginasta em efetuar uma boa impressão artística consiste em um atributo que deve ser desenvolvido e, no decorrer das aulas de dança, o atleta assimila o significado da arte.

Ainda de acordo com a $\mathrm{FIG}^{25}$, os exercícios utilizados para o ensino de balé exercem uma influência pronunciada no desenvolvimento do ginasta. MitChell et al. ${ }^{26}$ rememoram que grande parte dos movimentos de braços e pernas na GA é oriunda dessa prática corporal. Basta analisarmos o programa de desenvolvimento atlético da $\mathrm{FIG}^{25}$, Age Groups Development Program, para verificarmos a presença do balé na modalidade. Além disso, a própria FIG Academy, que promove cursos para técnicos de GA no mundo, reservam espaço para ministrar o conteúdo de preparação artística ${ }^{25}$. Poder-se-ia supor que, pelas características estéticas inerentes da dança, estas estariam harmonizadas com a estética da GA. Entretanto, o que encontramos comumente nesse modelo de treinamento da GA é uma postura que não adota o balé como arte, mas, como instrumento mecânico para o aprimoramento de gestos e postura. Ainda que o balé possua uma sistematização rígida de posturas, passos e alinhamentos, sua intenção final é expressiva e o contexto estético no qual se move é o do espetáculo artístico. O uso de uma disciplina do balé, descontextualizada do seu universo artístico, é uma ação que, do ponto de vista estético, assume uma atitude sectária e pragmática.

Notamos assim que, a impressão primeira de que o balé poderia ser um contraponto gestual e expressivo ao endurecimento da preparação física, que constrói um/a ginasta equilibrado/a e diversificado/a, mostra-se, ao contrário, redundante no intuito final: ambos os esforços são desconectados do sentido estético, e atendem a uma lógica própria, fundamentalmente pragmática. Uma discussão complementar poderia até mesmo colocar em questão se a rigidez do balé, por si só, já seria um fator de inadequação dessa prática como complemento à então rígida GA.

Pragmatismo e valor estético sempre tiverem relação conflituosa. Isso não indica dizer que aquilo que é belo mostra-se, necessariamente, inútil. Mas, por outro lado, do ponto de vista estético, aquilo que é belo não precisa ser, necessariamente, útil ${ }^{b}$. A partir de uma consideração estética esse é um entendimento que a GA precisa absorver caso deseje lidar com duas influências distintas, esporte e arte, no seu processo criativo. ARKAEv e SuCHILIN ${ }^{1}$ citam que a preparação artística na GA masculina não é mais necessária quando os atletas atingem o alto rendimento, pois receberam uma base adequada no desenvolvimento da sua carreira esportiva. Isso indica que essa preparação perde a sua utilidade e abre espaço para o caráter atlético considerado mais importante.

Como resultado desse endurecimento, por demais centrado na execução técnica de elementos de alto grau de dificuldade e pouco atento ao valor artístico, podemos verificar uma redundância expressiva, ou seja, em uma mesma competição (para fixarmos o espaço e o tempo da análise) encontraremos séries muito semelhantes entre si. O fato ocorre, pois, atualmente, tal como em muitos outros setores, o trânsito de informações é muito intenso e veloz. É 
bem pouco provável que muitos ginastas apresentem movimentos originais na composição das séries. A maioria delas será composta, com pouca variação, sem muitas surpresas. OliveIRA e BORTOLETO ${ }^{6}$ consideram que a valorização de determinados elementos no Código de Pontuação diminuiu a criatividade dos ginastas e direcionou os atletas a buscarem elementos de dificuldade com menor possibilidade de erros de execução. Outro aspecto que esses autores mencionam está relacionado à exclusão de vários elementos do Código de Pontuação que restringiu o repertório de habilidades que poderiam compor as séries dos atletas. BORTOLETO ${ }^{3}$ cita que a repetição dos mesmos elementos pelos ginastas retoma, de forma parcial, o aspecto monótono das competições obrigatórias que foram extintas após o ciclo 1993-1996.

Novamente, eis um fator no qual a característica artística da GA poderia oferecer um rico diferencial. A criação expressiva não tem amarras tão atadas e poderia oferecer coloraçóes diversas à mesma competição. Entretanto, pela pouca atenção à composição artística, corre-se o risco da mesmice. Somente o observador mais preparado é capaz de decupar a série e atribuir-lhe valor. Tornou-se comum, em transmissões televisivas de competições internacionais, que o locutor esteja acompanhado de um expert que faça a "leitura técnica" da série, e que ao final aponte o seu grau de qualidade. O observador mais geral fica à caça de desequilíbrios, escorregões ou quedas, que por si só seriam revezes bastante evidentes. Em respeito à opinião mais sensível que consideraria uma série "bonita", "vibrante", "enérgica", "divertida" etc. tem um sentido final de absoluta perfumaria no contexto da GA de competição.

Mais uma vez é preciso reforçar que o que estamos aqui argumentando não desqualifica a profundidade técnica da GA, que é uma característica evolutiva da modalidade, tampouco um preceito básico da competição que é diferenciar o campeão do nãocampeão. Não ignoramos as dificuldades inerentes de se avaliar com preocupaçôes estéticas. Mas, ao mesmo tempo, ao focarmos a GA a partir de um referencial estético, outros valores e inquietaçôes surgem e nossa tarefa aqui é justamente a de expor esses resultados, para assim ampliar as discussões neste campo.

\section{Por uma influência brasileira no desenvolvimento artístico da ginástica}

Até há pouco tempo, propor uma influência brasileira em qualquer aspecto da GA era um esforço válido, porém um tanto exorbitante frente à inexpressividade do Brasil no contexto internacional da modalidade.

Hoje, depois de resultados evidentes e de um trabalho estruturado, podemos dizer que o Brasil ganhou expressividade no contexto internacional da modalidade graças a uma estrutura física e humana, respaldada pelo investimento financeiro, que jamais houve na história da GA no Brasil ${ }^{27-28}$.

O sucesso obtido atualmente demonstrou que podemos nos equiparar às grandes potências mundiais. O Brasil tornou-se uma voz na modalidade, senão protagonista, ao menos emergente. Se por um lado, a história da Ginástica se confunde com a própria formação do povo europeu, que chegou a nós sob a forma de influência, por outro, uma das marcas mais evidentes da estética brasileira é a da mistura, do hibridismo e da inventividade. Exatamente esta mistura de raças, a miscigenação, fez surgir um povo criativo e espontâneo em expressão e sentimentos.
Em um primeiro momento da visibilidade do país no cenário internacional da GA parece ter havido uma preocupação, até certo ponto justificável, de se evidenciar referências nacionais (como músicas típicas, as cores da bandeira, aspectos culturais etc.). Atualmente, talvez seja possível um passo maior, pelo próprio potencial estético do país. No mais, como país ingressante no circuito mais elitizado da GA mundial, se por um lado temos o ônus da falta de tradição específica, pelas mesmas razões, estamos muito mais "livres" para inovaçôes e experimentaçōes.

É evidente que uma ação estética mais ousada corre riscos, mas, também, assume uma posição propositiva, ainda inédita para nós. Qualquer mudança no campo do esporte, pela sua polissemia e complexidade características, necessita que açōes em vários sentidos convirjam para fins razoavelmente específicos. Precisamos de discussões acadêmicas e de pesquisas científicas tanto quanto de iniciativas na prática do treinamento em GA. O que vislumbramos aqui não é a militância em torno de ações, defendendo essa ou aquela atitude como mais válida do que o conjunto dos esforços que já vêm sendo 
feitos pela modalidade no país. Trata-se, novamente, de perceber que, quando submetida a uma análise estética, a GA revela contornos que sob a influência de outras abordagens estavam latentes. Entre eles, a carência de inventividade parece ser um problema contra o qual o Brasil tem capacidade de superar, com propriedade e proveito.

Através da cultura e da criatividade brasileira, a nossa GA pode deixar a sua marca no cenário mundial. Isso ficou evidenciado quando o coreógrafo da seleção brasileira, Rhony Ferreira, passou a integrar o "roll" de especialistas da FIG Academy, ao abordar a preparação artística e coreográfica de solo e trave ${ }^{29}$.

A Estética não é uma metodologia de análise menos válida que outras no campo do esporte, mas, certamente, podemos notar que ela ainda é pouco utilizada. Ainda que uma dimensão muito evidente do esporte seja sua expressão estética, via de regra, não estamos acostumados a assumir essa dimensão como objeto de estudo. Esse paradoxo torna-se ainda mais patente em uma modalidade que se denomina "Ginástica Artística”.
Nesse artigo percebemos como a luz da Estética pode realçar contornos pouco evidentes sob outros enfoques escassamente explorados e, até mesmo, desconhecidos. A GA, sem dúvida, é uma das modalidades mais singulares no universo do esporte e, para tanto, precisa preservar sua idiossincrasia. É uma modalidade altamente técnica, mas, também, fundamentalmente expressiva e artística, ou seja, provoca a criatividade e a exploração. Um esporte belo, no sentido profundo que a Estética confere ao termo.

Mesmo que se priorize a competitividade, ainda assim a valorização dos componentes artísticos e estéticos pode ser um diferencial. Árbitros e técnicos poderiam estar sensíveis a isso, pois eles também reproduzem o que vivenciaram em gerações anteriores. É difícil valorizar ou canalizar atenção para este componente quando a técnica e a acrobacia são sinalizadores evidentes dos campeões na modalidade. Quando lembramos de um campeão, geralmente, recordamos de suas acrobacias. Mas, a brasileira Daiane dos Santos foi além, pois as pessoas associam sua figura com a coreografia, ao som do chorinho de Waldir Azevedo. Vale a pena refletir sobre isso.

\title{
Notas
}

a. Powell T, editor. The game: the Marshall Cavendish encyclopedia of world sports. London: Marshall Cavendish; 1971.

b. Um dos pilares fundamentais da discussão estética está na reflexão platônica entre o belo e o útil, tão pertinente aos desejos da pólis grega naquele momento, residentes no conceito de Kalokagathia.

\begin{abstract}
What artistic gymnastics has of artistic? Considerations from an aesthetical analysis

The terminology, Artistic Gymnastics, suggests a major role of the aesthetic aspect of this sport and points out an intersection between sport and art. This article discusses the premises of this intersection using the concepts from aesthetics field and the characteristics observed in the current context of this sport. It is noticed that one of the greatest wealth of this sport lies in the union between these two phenomena, but the artistic content has been overlooked, undervalued or underused in practice. Brazil can make his mark on Artistic Gymnastics world scenario through the combination, the hybridism and the inventiveness that are Brazilian aesthetic characteristics that can influence the expressive and artistic contents of this sport.
\end{abstract}

KEY woRDS: Aesthetics; Artistic gymnastics; Art; Code of points. 
Roble OJ, et al.

\section{Referências}

1. Arkaev L, Suchilin N. Gymnastics: how to create champions. Maidenhead: Meyer \& Meyer; 2004.

2. Palmer C. A qualitative investigation of aesthetic evaluation in men's artistic gymnastics [thesis]. Liverpool (UK): John Moores University; 2003.

3. Bortoleto MAC. O caráter objetivo e o subjetivo da ginástica artística [dissertação]. Campinas (SP): Universidade Estadual de Campinas, Faculdade de Educação Física; 2000.

4. Palmer C, Sellers V. Aesthetic heritage of men's artistic gymnastics for olympic competition. J Olympic History. 2009; 17:23-38.

5. Oliveira MS, Nunomura M. A produção histórica em ginástica e a constituição desse campo de conhecimento na atualidade. Conexōes. 2012;10:80-97.

6. Oliveira MS, Bortoleto MAC. O código de pontuação da ginástica artística masculina ao longo dos tempos. Rev Educ Fís./UEM. 2009;20:97-107.

7. Federação Internacional de Ginástica (FIG). Código de pontuação masculino. Brasília: Gráfica Alvorada; 1977.

8. Federação Internacional de Ginástica (FIG). Código de pontuação masculino. Brasília: Gráfica Alvorada; 1979.

9. Federação Internacional de Ginástica (FIG). Código de pontuação feminino 2013-2016. 2012. [citado 12 jan. 2013]. Disponível em: www.fig-gymnastics.com/rules.

10. Federação Internacional de Ginástica (FIG). Código de pontuação masculino 2013-2016. 2012. [citado 12 jan. 2013]. Disponível em: www.fig-gymnastics.com/rules.

11. Pires FR. Preparação artística na ginástica artística [dissertação]. São Paulo (SP): Universidade de São Paulo, Escola de Educação Física e Esporte; 2010.

12. Suassuna A. Introdução à estética. Rio de Janeiro: José Olympio; 2004.

13. Angeles P. Dictionary of philosophy. New York: HarperCollins; 1992.

14. Baumgarten AG. Estética. Petrópolis: Vozes; 1993.

15. Carchia G, D'Angelo P. Dicionário de estética. Lisboa: Ediçōes 70; 1999.

16. Abbagnano N. Dicionário de filosofia. São Paulo: Martins Fontes; 2003.

17. Comte-Sponville A. Dicionário filosófico. São Paulo: Martins Fontes; 2003.

18. Maloney S. Stretching out: code catastrophe! 2005. [citado 25 out. 2007]. Disponível em: http://www.gymmedia. com/FORUM/agforum/05_Maloney_e.htm.

19. Macur J. A 10 isn't necessarily perfect in new scoring system for gymnastics. 2008. [citado 06 mar. 2009]. Disponível em: http://www.nytimes.com/2008/08/06/sports/olympics/06scoring.html?pagewanted=1\&_r=1.

20. Powell D. New system marks end of the holy grail for gymnasts. 2006. [citado 06 mar. 2009]. Disponível em: http:// www.timesonline.co.uk/tol/sport/article741559.ece.

21. Nietzsche F. O nascimento da tragédia. São Paulo: Companhia das Letras; 2003.

22. Soares CL. Educação física: raízes européias e Brasil. Campinas: Autores Associados; 1994.

23. Soares CL. Imagens da educação no corpo. Campinas: Autores Associados; 1998.

24. Nunomura M, Pires FR, Carrara PDS. Análise do treinamento na ginástica artística brasileira. Rev Bras Ciênc Esporte. 2009;31:25-40.

25. Federation Internationale de Gymnastique (FIG). Age group development program. Montier: FIG; 2003.

26. Mitchell D, Davis B, Lopez R. Teaching fundamental gymnastics skills. Champaign: Human Kinetics; 2002.

27. Oliveira MS. O panorama da ginástica artística masculina brasileira: um estudo histórico-crítico do período 2005-2008 [dissertação]. Campinas (SP): Universidade Estadual de Campinas, Faculdade de Educação Física; 2010.

28. Nunomura M, Oliveira MS. Centro de excelência e ginástica artística feminina: a perspectiva dos técnicos brasileiros. Motriz. 2012;18:378-92.

29. Federação Internacional de Ginástica (FIG). FIG academy level 3 for artistic gymnastics, Lausanne: FIG; 2009. [citado 10 mar. 2012]. Disponível em: http://www.fig-gymnastics.com/vsite/vcontent/content/transnews/0,10869,5187188043-19728-44766-295686-18047-5233-layout188-205265-news-item,00.html. 
Odilon José Roble

Faculdade de Educação Física Universidade Estadual de Campinas Av. Érico Veríssimo, 701

13083-851 - Campinas - SP - BRASIL e-mail: roble@fef.unicamp.br
Recebido para publicação: 26/04/2012

Revisado: 24/02/2013

Aceito: 20/03/2013 